\title{
Pharmaceutical Compounds as Photostabilizers
}

\author{
Esraa Ismael Al-khateb*, Ahmed Ahmed** and Khalaf F Alsamarrai* \\ *Department of Chemistry, College of Education, Samarra University, Samarra-Iraq. \\ *** Polymer Research Unit, College of Science, Al- Mustansiryah University, Baghdad-Iraq.
}

\begin{abstract}
In this paper, some pharmaceutical compounds were used and their impact on the photostability of polymer poly (vinyl chloride) (PVC) was study. The PVC films containing a variant concentration of compounds $0.25,0.5,1 \%$ by weight were produced by casting method from tetrahydrofuran (THF) solvent. The photostabilization activities of these compounds were determined by calculating the photodegradation rate constant for photostabilizer $(\mathrm{kd})$. The stabilizing efficiency of pharmaceutical compounds is attributed to the replacement of the labile chlorine atoms on the PVC chains by a relatively more stable moiety of the pharmaceutical stabilizer. The Photostabilization activity of these compounds is determined by weight loss method with irradiation time.
\end{abstract}

Keywords: poly(vinyl chloride), photostabilizer, UV-Visible, pharmaceutical.

\section{Introduction}

Photochemical degradation can take place as a result of chemical reaction, or photochemical degradation, which could be initiated through the energy from UV solar radiation. Antioxidant materials are known as heat and light stabilizers that can be added to plastics to avoid its deterioration [1]. There is a great interest at present in the photodegradation of polymeric systems, and this is reflected in the large number of research papers and other scientific publications that appear each year in this area. A major reason for this interest is that macromolecular materials have increasingly wide commercial applications where outdoor durability is an important consideration [2-5].
Degradation also causes a drastic change in theme chanical properties of the polymer, which is accompanied by a decrease or increase in its average molecular weight as a result of either chain scission or cross-linking of the polymer molecules, respectively [6-11].

\section{Materials}

All used organic compounds (additions of PVC) (supplied by company Fluka) and used as received without further purification. organic compounds are:

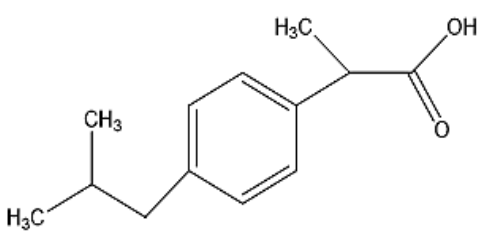

Compound (1) 2-(4-isobutylphenyl)propanoic acid

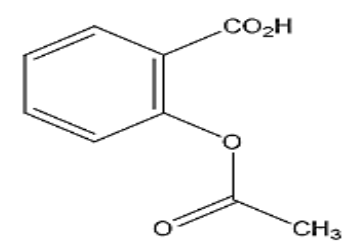

Compound (3) 2 -acetoxybenzoic acid<smiles>CC(=O)Cc1ccccc1Nc1c(Cl)cccc1Cl</smiles>

compound(2) sodium 2-(2-((2,6-dichlorophenyl)amino)phenyl)acetate<smiles>CC(=O)Nc1ccc(O)cc1</smiles>

Compound (4) $N$-(4-hydroxyphenyl)acetamide 


\section{Experimental Techniques:}

Films preparation [12]

The best solvent for PVC is tetrahydrofuran. Fixed concentrations of PVC solution $(5 \%)$ in THF were used to prepare polymer films with $80 \mu \mathrm{m}$ thickness by evaporation technique at room temperature for 24 hrs. The used organic compounds (additions) $(0.25 \%, 0.5 \%, 1 \%)$ concentrations by weight) were added to the films starting at zero concentrations (blank). It was necessary to control the hygrometry and the rate of evaporation of solvent during casting to maintain good optical quality and very limited turbidity. After complete dissolution, the resulting solution was spread on glass frame and left overnight. This frame was made by glue the laboratory glass slides on a piece of regular glass, to obtain small sinks, their volume is $(4 \mathrm{ml})$. The films that formed upon complete evaporation of the solvent at room temperature were pasted on cartoon papers contain hole in dimension $(2 \times 2) \mathrm{cm}$.

\section{Irradiation Experimental}

\section{Accelerated testing technique:}

UV light was used for irradiation of polymer films. The lamp giving spectrum range between (250-380) $\mathrm{nm}$ and the light intensity is $6.2 \times 10^{-9}$ ein $\mathrm{dm}^{-3} \mathrm{sec}^{-1}$. The polymer films samples were fixed vertically and parallel to the lamps to sure that UV incident radiation is vertically incident on the samples, the irradiation samples change places from time to time to be sure that the intensity of light incident on all sample is equal. The distance be between the polymer films and light source was $10 \mathrm{~cm} \mathrm{[13].}$

\section{Measuring the photodegradation rate of polymer films using Ultraviolet-visible spectrophotometer [14]}

Ultraviolet-visible spectrophotometry technique was used to measure the changes in the UV-Visible spectrum during different irradiation times for each polymer film at maximum absorption band $(\lambda \max =200-400$ $\mathrm{nm})$. The photodegradation rate constant for the Photostabilizer (kd) was calculated using the first order kinetic equation

$$
\ln (\mathrm{a}-\mathrm{x})=\ln \mathrm{a}-\mathrm{k}_{\mathrm{d}} \mathrm{t}
$$

where: $\mathrm{a}=$ the additive concentration before irradiation

$\mathrm{x}=$ the additive concentration after irradiation time ( $\mathrm{t}$ in $\mathrm{sec})$.

If Ao represents the absorption intensity of the polymer film containing additive before irradiation, $A \infty$ intensity at infinite irradiation time and At is the absorption intensity represents the absorption after irradiation time $\mathrm{t}$, then :

$$
\begin{aligned}
\mathrm{a} & =\mathrm{A}_{\mathrm{o}}-\mathrm{A}_{\infty} \\
\mathrm{x} & =\mathrm{A}_{\mathrm{o}}-\mathrm{A}_{\mathrm{t}} \\
\mathrm{a}-\mathrm{x} & =\mathrm{A}_{o}-\mathrm{A}_{\infty}-\mathrm{A}_{\mathrm{o}}+\mathrm{A}_{\mathrm{t}}=\mathrm{A}_{\mathrm{t}}-\mathrm{A}_{\infty}
\end{aligned}
$$

Substitution of (a) and (a-x) from equations (2) in (1) gives:

$$
\ln \left(\mathrm{A}_{\mathrm{t}}-\mathrm{A}_{\infty}\right)=\ln \left(\mathrm{A}_{o}-\mathrm{A}_{\infty}\right)-\mathrm{k}_{\mathrm{d}} \mathrm{t}
$$

Thus the plot of $\ln ($ At $-A \infty)$ versus irradiation time $(\mathrm{t})$ gives straight line with a slope equal to $(\mathrm{kd})$. This indicates that photodecomposition of the additive in first order.

\section{Measuring the photodegradation by weight loss [15]}

The stabilizing potency of the stabilizer was determined by measuring the weight-loss percentage of photodegraded PVC films in absence and in presence of additives. The weight loss measurements were carried out according to the following equation;

Weight loss $\%=\left[\left(\mathrm{W}_{1}-\mathrm{W}_{2}\right) / \mathrm{W}_{1}\right] \times 100$

Where $\mathrm{W}_{1}$ is the weight of the original sample (before irradiation) and $\mathrm{W}_{2}$

is the weight of sample after irradiation.

\section{Results and Discussion}

Measuring the photodegradation rate of polymer films using Ultraviolet-visible spectrophotometer

Ultraviolet radiations are known to have deleterious effects on most industrial polymers inducing chemical modification and scission of polymer chain, which ultimately lead to an undesirable loss of the mechanical and surface properties of the irradiated material [16]. Poly (vinyl chloride) suffers from poor thermal and light stability. The prepared organic compounds were used as photostabilizers to 
Poly (vinyl chloride) films comparing with Poly (vinyl chloride) films (blank). The physical properties of additives and polymers play a very important role in determining the additive efficiency in photostabilization or photodegradation of polymers [17] The additives used in this study were chosen to be completely soluble in polymer solvent, THF. It has been noticed that the additives used in the present work are photodecomposed during the photolysis. Thus the photodecomposition rate constant $(\mathrm{kd})$ was calculated (see paragraph (3.1)). The (kd) values were computed using the UV spectra changes of PVC films thickness $(80 \mu \mathrm{m})$ containing $0.25,0.5,1 \%$ of additives. The plot of irradiation time versus $\ln$ $($ At-A $\infty)$, gives straight line which indicates primarily the first order reaction. The slope equal to the decomposition rate constant $\mathrm{kd}$.

The values of the first order rate constant of all the additives decay in PVC films (kd) calculated by the same way and shown in Table (1).

Table (1)

Photodecomposition rate constant $(k d)$ of PVC films (80 $\mu \mathrm{m})$ thickness containing $(0.25,0.5,1) \%$ of additives.

\begin{tabular}{|c||c||c||c||}
\hline \%w/w & $\begin{array}{c}\text { Conc. } \\
\mathbf{0 . 2 5}\end{array}$ & $\begin{array}{c}\text { Conc. } \\
\mathbf{0 . 5}\end{array}$ & Conc. 1 \\
\hline \hline pvc & 2E-06 & 2E-06 & 2E-06 \\
\hline \hline PVC+Comp.(1) & $2 \mathrm{E}-07$ & $3 \mathrm{E}-07$ & 4E-07 \\
\hline \hline PVC+Comp.(2) & $4 \mathrm{E}-07$ & $5 \mathrm{E}-07$ & $6 \mathrm{E}-07$ \\
\hline \hline PVC+Comp.(3) & 7E-07 & $8 \mathrm{E}-07$ & 9E-07 \\
\hline \hline PVC+ Comp.(4) & 9E-07 & 1E-06 & 1.9E-06 \\
\hline
\end{tabular}

The photostabilizers always posses low kd values, which mean that these modified polymers are stable towards UV light. One could notice that $\mathrm{kd}$ values are sensitive to the type of additives in Poly(vinyl chloride) films, which decrease in the following order:

$$
\text { PVC (blank) > (5)> (4) > (3) > (2) > (1) }
$$

PVC with additives

And this might point out to increase the photostability of this additives in this term. Results showed that decrease the concentrations of the additive lead to increase the photostability of polymeric films.
Measuring of the Stabilizing Efficiency for Poly(vinyl chloride)Films by Weight Loss Method

The photodegradation of Poly(vinyl chloride) is commonly known to be accompanied by a dehydrochlorination process (the evolution of $\mathrm{HCl}$ gas); consequently, weight loss occurs, which increases with the increasing of irradiation time. Thus, the weight-loss percentage as a function of the irradiation time can be a good measure of the degree of degradation and consequently can measure the stabilizing potency of the stabilizer and how long that stabilizer would protect the polymer. Weight loss measurements were carried out according to the following equation:

Weight loss \% $=\left[\left(\mathrm{W}_{1}-\mathrm{W}_{2}\right) / \mathrm{W}_{1}\right] \times 100$

Where :

$\mathrm{W}_{1}$ : is the weight of the original sample (before irradiation).

$\mathrm{W}_{2}$ : is the weight of the sample (after irradiation).

The results of the weight loss as a function of the irradiation time are shown in Figs.(1,2 and 3). This results clearly show the low extent of weight loss (i.e., the low extent of dehydrochlorination as evolved $\mathrm{HCl}$ is the main degradative product) of photodegraded Poly(vinyl chloride) stabilized by organic compounds in comparison with the weight loss of photodegraded unstabilized PVC, and shows that the compound (1) more effective stabilizer than others [18]. Thus the stabilizing efficiency of the investigated photostabilizers was found to follow this order:

Comp. (1)>Comp. (2)>Comp. (3)>Comp. (4) 


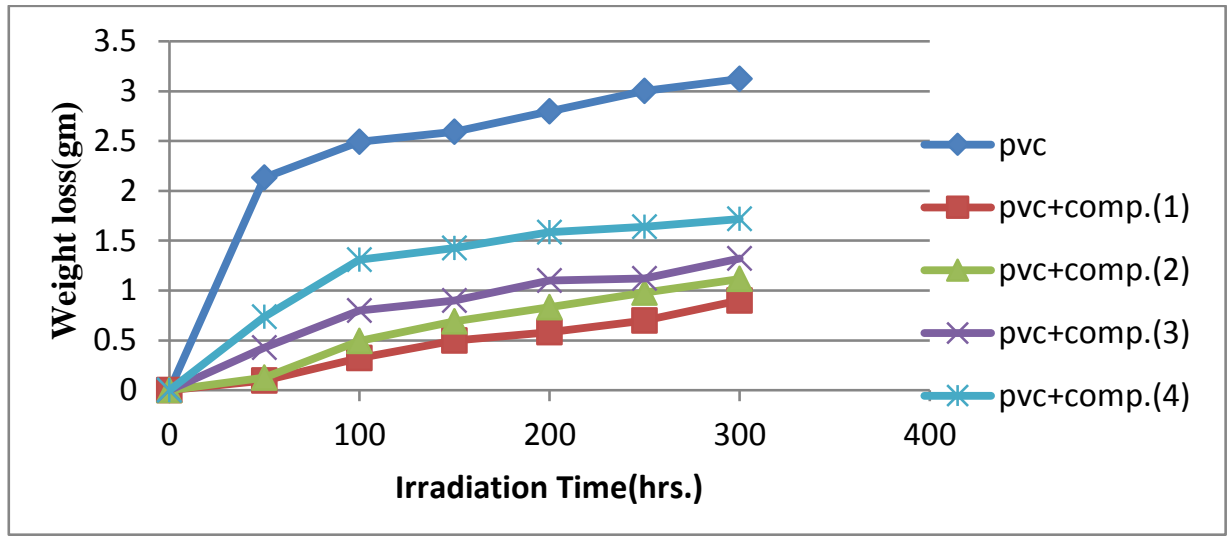

Fig. (1): Variation of the weight loss of PVC films $(80 \mu m)$ thickness containing $0.25 \%$ additives with the irradiation time.

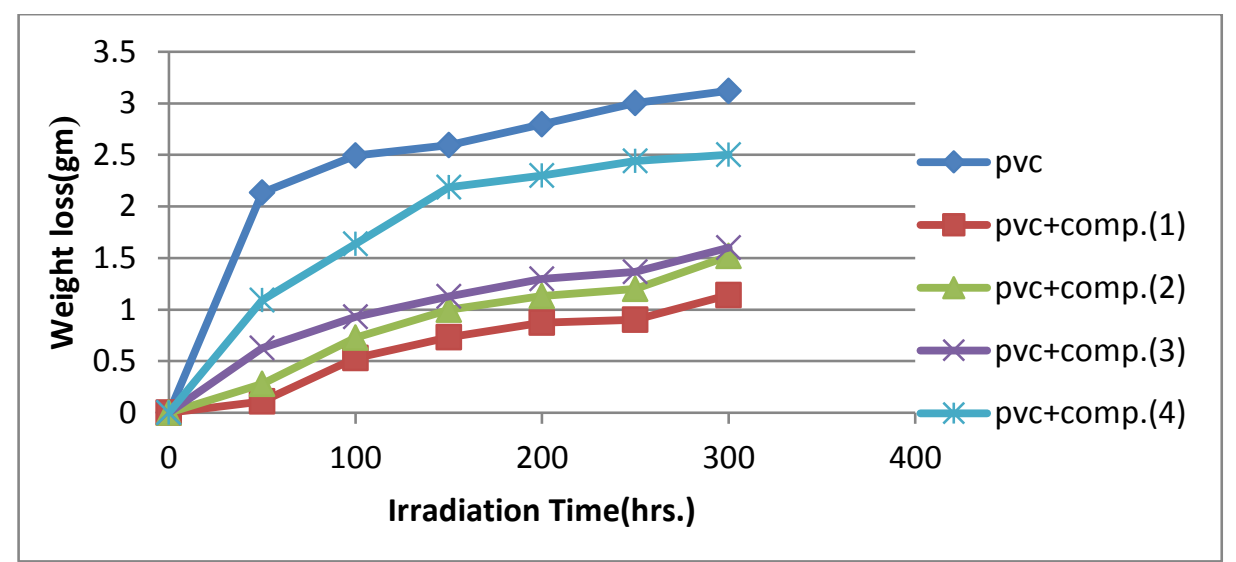

Fig. (2): Variation of the weight loss of PVC films $(80 \mu m)$ thickness containing $0.5 \%$ additives with the irradiation time.

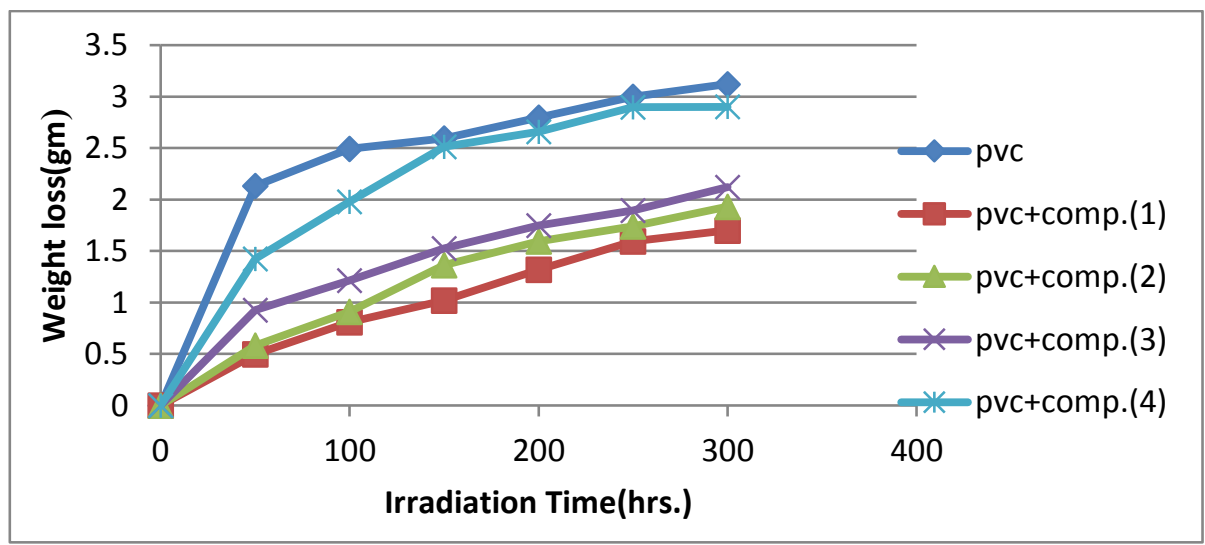

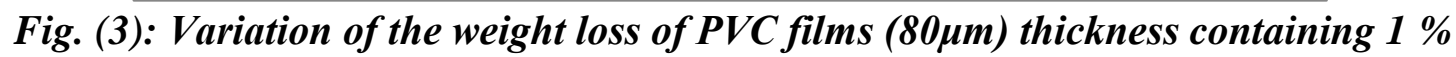
additives with the irradiation time.

\section{Acknowledgement}

We gratefully acknowledged the funding from the Chemistry Department in College of Education, Samarra and College of Science, Al-Mustansiriyah University.

\section{References}

[1] Chmela, Š., Lajoie, P., Hrdlovǐc, P., Lacoste, J., Combined oligomeric light and heat stabilizers. Polym. Degrad. Stab., 71:171-177, 2001.

[2] Torikai A. and Hasegawa H., Accelerated photodegradation of poly(vinyl chloride), Polym. Degrad. Stab., 63: 441-445,1999.

[3] Kaczmznek, H., Kowaloneck, J., and Oldak, D., Physical Morphology and Quantittive Characterization of Chemical Weathered PVCLPine Composites. Journal 
of polymer Environmental. 18: 57-64, 2009.

[4] Chanda, M., and Roy, S. K., Plastics Technology Handbook, $3^{\text {rd }}$ Ed, Marcel Dekker Inc, New York, 1998.

[5] Yousif, E., Hameed, A., Rasheed, R., Mansoor , H., Farina, Y., Graisa, A., Salih, N., and Salimon, J., Synthesis and Photostability Study of Some Modified Poly(vinyl chloride) Containing Pendant Benzothiozole and Benzomidozole Ring. International Journal of Chem. 2: 65-80, 2010.

[6] Yousif, E., Salih, N., Salimon, J., Improvement of the photostabilization of PVC films in the presence of $2 \mathrm{~N}$ salicylidene-5-(substituted)-1,3,4-

thiadiazole, J. Appl. Polym. Sci. 120 2207-2214, 2011.

[7] Braun, D., Rabie, S., Khaireldin, N. M., Abd El-Ghaffar, Prepa-ration and evaluation of some benzophenone terpolymers asphotostabilizers for rigid PVC, J. Vinyl Addit. Technol. 17 47-155, 2011.

[8] Yousif, E., Salimon, J., and Salih N., New Photostabilizers for PVC Based on Some Diorganic (IV) Complexes. journal of Saudi Chemical Society. in press, 2012.

[9] Sabaa, W., Rabie, T. S., and Mohammed, R. R., Novel Antimicrobial and Antitumor Organic Thermal Stabilizers for Rigid Poly (vinyl chloride. Journal of Ther anacalorim. 109: 1503-1513, 2012.

[10] Ivan, B., Kenedy, J. P., Kelen, T., and Toudos, F., Nagy, T. T., Torscanyi, B., Degradation of PVC Obtained by Controlled Chemical Dehydrochlorination. Journal of Polymer Science. 21: 2177-88, 1983.

[11] Rasheed, R., Mansoor, H., Yousif, E., Hameed, A., Farinay, Y., and Graisa, A., Photostabilizing of PVC Films by 2-(aryl)1,5-[4-(aryloxy)-Phenyl]-1,3,2-Oxadiazole Compounds. Eur. J. Sci. Res. 30: 464-477, 2009.

[12] Shneshil M. and Redayan M., Photostabilization of PVC films by using some novel tetra Schiff's bases derived from1,2,4,5-tetra- [5-amino-1,3,4thiadiazole-2-yl]-benzene, Diyala $j$. for pure science, 7(1): 34-77, 2010.
[13] Yousif, E., Hameed, A., and Bakir, E., Synthesis and photochemical Study of poly (vinyl chloride)-1,3,4-oxadiazole and1,3,4Thiadiazole. Journal of Al-Nahrain University. 10(1): 7-12, 2007.

[14] Hussain, Z., Yousif, E., Altaie, A., and Zageer, D., Study the Rate Constant of Photostabilization of PVC in Presence of Schiff's Bases of Sulphamethoxazole, J. Al- Nahrain University., 17(4):39-43, 2014.

[15] Rabie, S.T., Ahmed, A.E., Sabaa, M.W., and Abd El-Ghaffar, M.A., Maleic diamides as photostabilizers for polystyrene. J. Ind. Eng. Chem., 19, 18691878, 2013.

[16] Yousif, E., Photostabilization of PVC: principle and applications. lambert, Germany, 2012.

[17] Gugumns, F., Development in polymer photostabilization-1, (G. Scott, ed.), Applied Science Publisher Ltd, London, 261-272, 1979.

[18] Sabaa, M. , Oraby, E., Abdel Naby, A., and Mohamed, R., N-Phenyl-3-substituted5-pyrazolone Derivatives as Organics Stabilizers for Rigid Poly(vinyl chloride) Against Photodegradation. Journal of Applied Polymer Science. 101: 1543-1555, 2006.

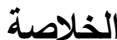

في هذا البحث, استخدمت بعض المركبات الدوائية

ودراسة تأثيرها على الاستقرارية الضوئية لمتعدد كلوريد

الفينيل. نم انتاج الرقائق البلاستيكية التي تحتوي على تراكيز

مختلفة 0.25\% و \% 0.5 و 1 \% وزناً من المركبات بطريقة

الصب من مذيب رباعي هيدرو فيوران. وحددت فعالية

الاستقرارية الضوئية للمركبات عن طريق حساب ثنابت سرعة

التحلل الضوئي للمثبت الضوئي. سبب كناءة التثبيت لهنيت

بالمركبات الدوائية هو استبدال ذرات الكلور في سلاسل متعدد

كلوريد الفينيل بمجموعة اكثر استقرارا نسبة للمثبت المستخدم.

وتم تحديد فعالية التثبيت الضوئي لهذه المركبات بطريقة

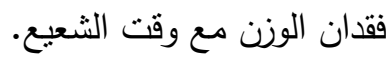

